\title{
Unusual Case of Low-Velocity Large Object Penetrating the Frontal Bone with Favorable Outcome: A Case Report in Pediatric Patient
}

\author{
Elvita Rahmi Daulay* (i) \\ Department of Radiology, Faculty of Medicine, Universitas Sumatera Utara, Medan, Indonesia
}

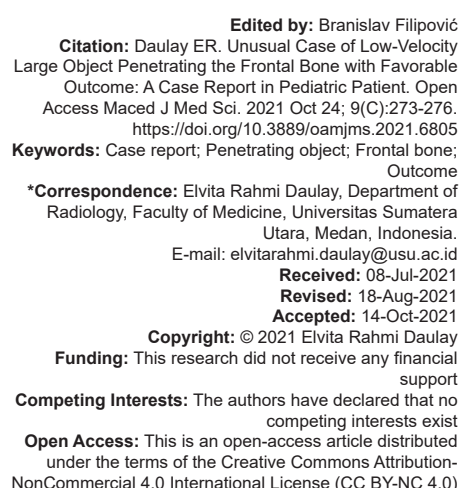

Edited by: Branislav Filipovic Citation: Daulay ER. Unusual Case of Low-Velocity Citation: Daulay ER. Unusual Case of Low-Velocity Large Object Penetrating the Frontal Bone with Favorable
Outcome: A Case Report in Pediatric Patient. Open Access Maced J Med Sci. 2021 Oct 24; 9(C):273-276 https://doi.org/10.3889/oamjms.2021.6805
Keywords: Case report; Penetrating object; Frontal bone; *Correspondence: Elvita Rahmi Daulay, Department of Radiology, Faculty of Medicine, Universitas Sumater Utara, Medan, Indonesia.
E-mail: elvitarahmi.daulay@usu.ac.id Received: 08-Jul-2021 Revised: 18-Aug-202 Copyright: ๑ 2021 Elvita Rahmi Daulay Copyright: $\odot 2021$ Elvita Rahmi Daulay
Funding: This research did not receive any financial Competing Interests: The authors have declared that no competing interests exis Open Access: This is an open-access article distributed under the terms of the Creative Commons Attribution-

\begin{abstract}
BACKGROUND: Penetrating head injury is one of the deadliest forms of head trauma; the outcome is usually low and patients who survive long enough require complex medical treatment. Immediate imaging assessment with appropriate management can improve patient recovery.

CASE REPORT: We reported a case of head penetration trauma on a 12-year-old child with embedded cylindrical iron that enters the skull without any signs of neurological deficit.

CONCLUSIONS: This case shows that aggressive diagnostic imaging and emergency care followed by proper immediate head surgery management and postoperative intensive care to monitor and intervene in possible surgical
\end{abstract} and medical complications could significantly improve patient outcomes.

\section{Introduction}

Penetrating head injury or penetrating traumatic brain injury (TBI) is a type of injury in which a missile breaches the skull but does not exit it [1]. Penetrating TBI cases are rare which about $0.4 \%$ of all of head injuries and have high morbidity and mortality [2]. Most of the literature regarding penetrating $\mathrm{TBI}$ were rare in accordance with the number of occurrences [3]. In low and middle-income countries, TBI is the leading cause of trauma-related death and disability [4].

Penetrating TBI can be divided into low-velocity and high-velocity injuries. A speed of $300 \mathrm{~m} / \mathrm{s}$ is considered the cut-off between low- and high-velocity injuries [5]. In this case report, we present low-velocity injury of penetrating TBI. Cases of penetrating TBI caused by nonmissile, low-velocity objects frequently occur accidentally. Low-velocity penetrating TBI depicts a unique pathology with a more favorable outcome due to the localized primary injury [6], [7].

Immediate radiological examination is mandatory to determine the extent of head penetration, the penetrating foreign body's location, and the necessity for surgery. Skull plain X-ray, although of less importance, can indicate the location of the foreign body and shows the nature of the depressed skull fragments.
In this situation, the essential radiological diagnostic tool is the brain computed tomography (CT) scan for both the soft tissue and bone windows. It can show any associated hematomas, brain contusions, and the extent of skull injury, thus aiding the management plan [8], [9], [10].

\section{Case Report}

A 12-year-old girl, about $9 \mathrm{~h}$ before admission, was practicing the marching band routine. During the exercise, the trainer threw the majorette stick up, but the stick hit the ceiling and broke, then one of the broken parts fell into and stuck in the patient's forehead. The strike was strong enough to be embedded about $1 \mathrm{~cm}$ deep into the frontal bone. There was minimal bleeding at the time of the incident. The patient remains alert in a panic condition (Figure 1). Since the incident, there was no altered mental state, neither seizure, and bleeding from the nose or ears (Figure 2). The patient vomited 3 times and nonprojectile. The patient was then referred to our hospital.

The head CT scan revealed fractures in the frontal bone with a minimal impression; no brain 


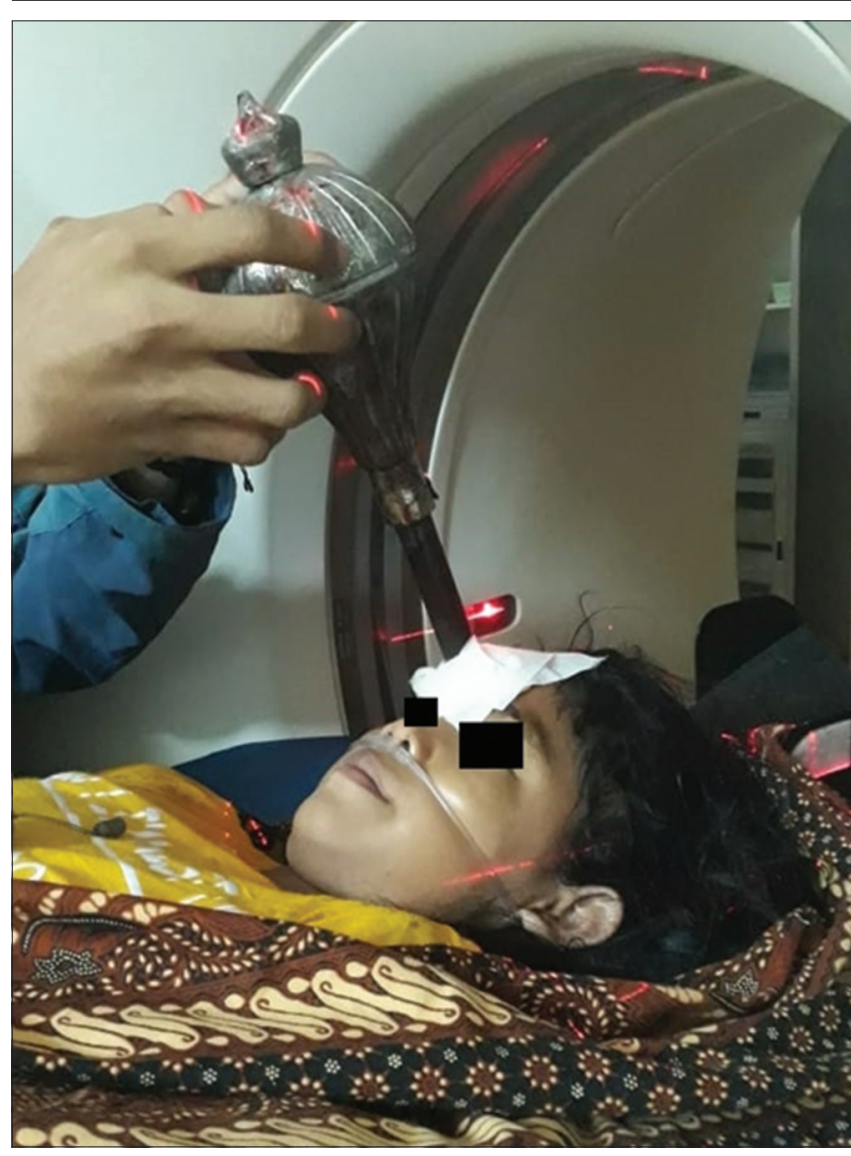

Figure 1: State of the patient during the computed tomography scan. The patient is cooperative and calm. The majorette stick is held manually during the examination to maintain its position

pathology was found (Figures 3 and 4). After the CT scan was conducted, the neurosurgeon could efficiently plan the surgery to extract the stick. After surgical extraction, the patient was observed and treated for

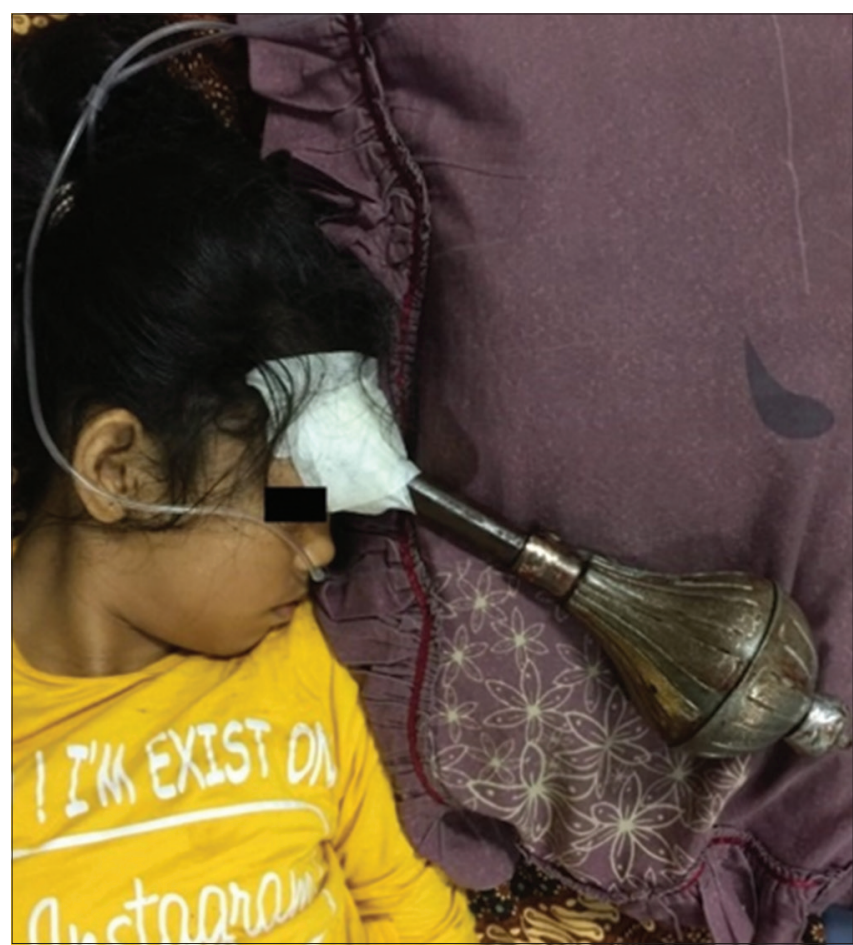

Figure 2: Patient' position while waiting for the examination process
5 days without any symptoms of neurological deficits, and the patient was finally allowed to go home.

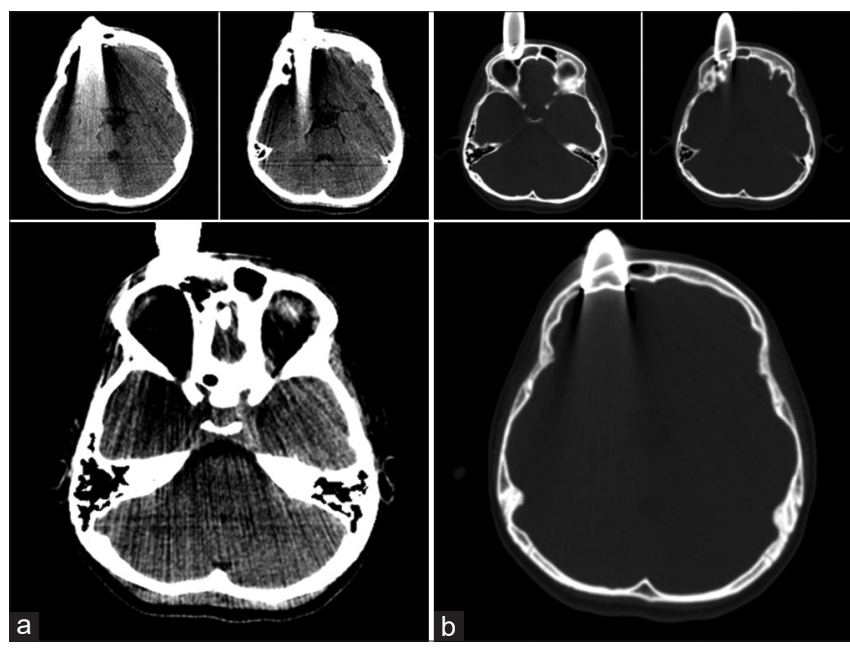

Figure 3: Non-contrast head computed tomography axial plane (a) brain and a (b) bone window showed the extent of the object and the brain structure involved

One of the problems we faced when performing the CT scan is the foreign object stuck in the head was long enough so that it is difficult to position the patient to fit in the CT scan gantry.

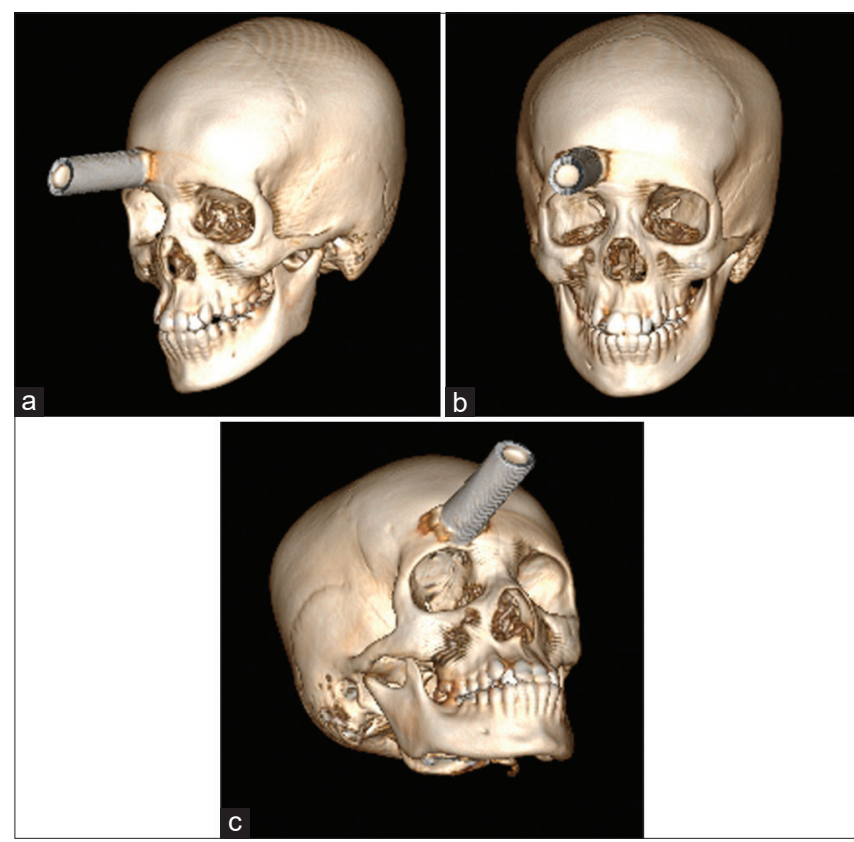

Figure 4: (a-c) Three-dimensional reconstruction of the head computed tomography showed the shape and exact location of the object

\section{Discussion}

Mass and velocity determine the severity of the injury [11]. Most missile objects other than bullets provide less and more localized damage to the skull and brain because of their lower velocity [12]. In our case, the object penetrates using the kinetic energy 
generated from its mass, considering its low-velocity setting, which is quite rare.

Penetrating TBI injuries can be classified into tangential wounds, penetrating wounds, perforating wounds, ricochet, and careening (Figure 5) [12]. Assessing the types of penetrating TBI can help with surgery planning, especially to anticipate complications and stratify prognosis [13]. Judging by its morphology, the penetrating TBI that occurred in our patient was a penetrating wound, although there was no clinical nor radiological brain involvement. In our case, the object was a majorette stick, fell with enough velocity to penetrate the frontal bone but leave the brain parenchyma intact.

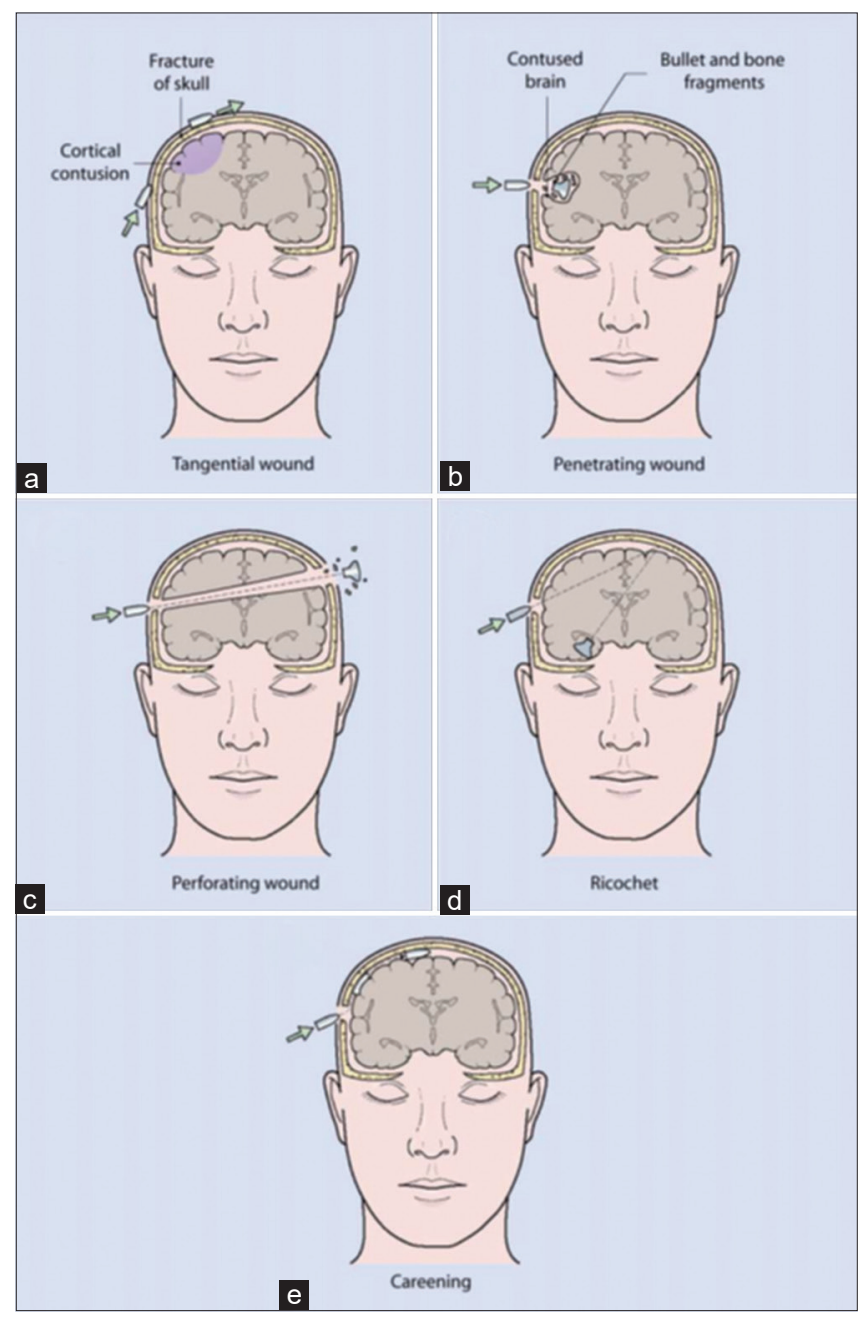

Figure 5: (a-e) Classification of penetrating traumatic brain injury (AbdulAzeez et al.)

TBI clinical features include prolonged coma, headache, nausea, aphasia, seizures, amnesia, and behavioral abnormalities such as aggression and anxiety, which occur within seconds to minutes after $\mathrm{TBI}$; however, some of these manifestations can persist up to a more extended period [14].

CT scan had been reviewed and accepted as the modality of choice for imaging evaluation of the acute TBI [15]. It is non-invasive and widely accessible instrument and has few contraindications. CT advantages for TBI assessment include its sensitivity for confirming acute hemorrhage, mass effect, ventricle size, and fractures. Disadvantages include its low sensitivity for detecting small non-hemorrhagic lesions such as contusions and diffuse axonal injuries and early ischemic encephalopathy [16]. CT with threedimensional reconstruction can fully show the shape, size, length, direction, and position of the object in three dimensions, which is beneficial for effective surgery planning [7].

The incidence of any neurosurgery intervention in the general pediatric trauma population is small, ranging roughly from $0 \%$ to $8 \%$ [17]. In accordance with our case, several studies have tried to predict which imaging or clinical findings in children with GCS scores $\geq 14$ would require neurosurgical involvement. Mackel et al. showed that intracranial findings or decrease of consciousness might be predictive for future intervention [18]. Addioui et al. reported that only $4.4 \%$ of 180 patients required neurosurgical intervention [19]. These studies suggest that the typical fracture requiring neurosurgical intervention results from a severe injury mechanism, neurological deficits, and obvious skull fracture. In our case, we could identify the frontal fracture and severe mechanism of injury, despite no neurological deficit nor altered mental status. Even with a seemingly severe kind of penetrating injury, the CT revealed no critical findings other than the frontal bone fracture. All of that emphasizes the importance of crosssectional imaging in emergency TBI.

\section{Conclusions}

The patient was discharged in good condition without any neurological deficits or disabilities. It took more than $8 \mathrm{~h}$, beginning at the initial complex evaluation process, to foreign body extraction surgery. Ours is a unique case where a foreign object that penetrates the head could cause far more critical injury to the brain tissue, resulting in most cases. Radiological examination is one of the main workups that play an essential role in supporting planning complex surgery.

\section{References}

1. Fahde Y, Laghmari M, Skoumi M. Penetrating head trauma: 03 Rare cases and literature review. Pan Afr Med J. 2017;28(1):305. https://doi.org/10.11604/pamj.2017.28.305.10376

2. Zhang D, Chen J, Han K, Yu M, Hou L. Management of penetrating skull base injury: A single institutional experience and review of the literature. Biomed Res Int. 2017;2017:2838167. https://doi.org/ 10.1155/2017/2838167.

PMid:28828384 
3. Buitendag JJ, Ras A, Kong VY, Bruce JL, Laing GL, Clarke $\mathrm{DL}$, Brysiewicz P. An overview of penetrating traumatic brain injuries at a major civilian trauma centre in South Africa. South Afr J Surg. 2019;57(1):37-42. https://doi. org/10.17159/20785151/2018/ v57n1a2711

4. laccarino C, Carretta A, Nicolosi F, Morselli C. Epidemiology of severe traumatic brain injury. J Neurosurg Sci. 2018;62(5):53541. https://doi.org/10.23736/S0390-5616.18.045 32-0 PMid:30182649

5. Moussa WM, Abbas M.Management and outcome of low velocity penetrating head injury caused by impacted foreign bodies. Acta Neurochir (Wien). 2016;158(5):895-904; discussion 904. https://doi.org/10.1007/ s00701-016-2764-x PMid:26973055

6. Lan ZG, Richard SA, Li J, Yang C. Nonprojectile penetrating iron rod from the oral cavity to the posterior cranial fossa: A case report and review of literature. Int Med Case Rep J. 2018;11:41-5 https://doi.org/10.2147/IMCRJ. S157237 PMid:29563841

7. Li XS, Yan J, Liu C, Luo Y, Liao XS, Yu L, et al. Nonmissile penetrating head injuries: Surgical management and review of the literature. World Neurosurg. 2017;98:873.e9-25. https://doi. org/10.1016/j.wneu.2016.11.125

PMid:27931948

8. Vakil MT, Singh AK. A review of penetrating brain trauma: Epidemiology, pathophysiology, imaging assessment, complications, and treatment. Emerg Radiol. 2017;24(3):301-9. https://doi.org/10.1007/s10140-016-1477-z PMid:28091809

9. Zyck S, Toshkezi G, Krishnamurthy S, Carter DA, Siddiqui A, HazamaA, etal.Treatment of penetrating nonmissile traumatic brain injury. Case series and review of the literature. World Neurosurg. 2016;91:297-307. https://doi.org/10.1016/j. wneu.2016.04.012 PMid:27072332

10. Schweitzer AD, Niogi SN, Whitlow CT, Tsiouris AJ. Traumatic brain injury: Imaging patterns and complications. Radiographics. 2019;39(6):1571-95. https://doi.org/10.1148/rg.2019190076 PMid:31589576
11. Young L, Rule GT, Bocchieri RT, Walilko TJ, Burns JM, Ling G. When physics meets biology: Low and high-velocity penetration, blunt impact, and blast injuries to the brain. Front Neurol. 2015;6:89. https://doi.org/ 10.3389/fneur.2015.00089 PMid:25999910

12. Van Wyck DW, Grant GA, Laskowitz DT. Penetrating traumatic brain injury: A review of current evaluation and management concepts. J Neurol Neurophysiol. 2015;6(6):336-43.

13. AbdulAzeez MM, Dolachee AA, Huber PZ, Romario MF, Obaid $\mathrm{H}$, Arakwazi $\mathrm{AH}$, et al. Intracranial ricocheted-bullet injuries: An overview and illustrative case. J Acute Dis. 2018;7(5):1862018. https://doi.org/10.4103/2221-6189.244165

14. Galgano M, Toshkezi G, Qu X, Russell T, Chin L, Zhao LR. Traumatic brain injury: Current treatment strategies and future endeavors. Cell Transplant. 2017;26(7):1118-30. https: //doi. org/10.1177/0963689717714102 PMid:28933211

15. Rincon-Guio $\mathrm{C}$. The role of computed tomography as a prognostic tool in traumatic brain trauma, Hospital; 1971.

16. Temple N, Donald C, Skora A, Reed W. Neuroimaging in adult penetrating brain injury: A guide for radiographers. J Med Radiat Sci. 2015;62(2):122-31. https:// doi.org/10.1002/jmrs.101 PMid:26229677

17. Kommaraju K, Haynes JH, Ritter AM. Evaluating the role of a neurosurgery consultation in management of pediatric isolated linear skull fractures. Pediatr Neurosurg. 2019;54(1):21-7. https://doi .org/10.1159/000495792 PMid:30673671

18. Mackel CE, Morel BC, Winer JL, Park HG, Sweeney $M$, Heller RS, et al. Secondary overtriage of pediatric neurosurgical trauma at a level i pediatric trauma center. J Neurosurg Pediatr. 2018;22(4):375-83. https://doi. org/10.3171/2018.5.PEDS182 PMid:29957140

19. Addioui A, Saint-Vil D, Crevier L, Beaudin M. Management of skull fractures in children less than 1 year of age. J Pediatr Surg. 2016;51(7):1146-50. https://doi.org/10. 1016/j. jpedsurg.2016.01.007 